\title{
Utilization of Rice Husks and Groundnut Shells for Bioethanol Production
}

\author{
Abdullahi Bako Rabah, Solomon Bankole Oyeleke, Shuaibu Bala Manga, and Lawal Hassan Gusau
}

\begin{abstract}
In the study rice husks and groundnut shells were hydrolysed with 3,4 and $5 \%$ concentrations of dilute hydrochloric acid and the reducing sugar concentration was determined using the dinitrosalicylic acid (DNS) colorimetric method. The concentration of the bioethanol produced was determined using the potassium dichromate method. The results revealed that there is no significance difference $(p<0.05)$ in the yields of the reducing sugar obtained from the substrates at different treatment conditions $(0.46 \mathrm{mg} / \mathrm{l}$ from rice husks at $3 \%, 400 \mathrm{C}$ for 30 minutes, $0.45 \mathrm{mg} / \mathrm{l}$ from groundnut shells at $4 \%, 30 \mathrm{oC}$ for 25 minutes and $0.46 \mathrm{mg} / \mathrm{l}$ from rice husks and groundnut shells at $5 \%, 300 \mathrm{C}$ for 30 minutes). Similarly, the result revealed that both $S$. cerevisiae and $Z$. mobilis produced their highest bioethanol concentrations of $0.58 \%$ and $0.54 \%$ respectively from rice husks after 24 hours of fermentation while their combination produced its highest concentration (0.524\%) after 72 hours. It is evidently clear that there despite the fact that there was no significance difference $(p<0.05)$ in the yields of bioethanol produced by $S$. cerevisiae and $Z$. mobilis, $S$. cerevisiae proved to be a better choice in bioethanol production using these substrates that either $Z$. mobilis or their combination.
\end{abstract}

Index Terms-Bioethanol, groundnut shells, rice husks, production, utilization.

\section{INTRODUCTION}

In recent years the World has witnessed a tremendous increase in the search and quest for an alternative energy source to replace the convectional fossil fuels. This was necessitated as a result of the finite nature of crude oil and other fossil fuels. Another reason was the immense contribution of these products to environmental degradation, environmental pollution and to cap it all their contribution in enhancing green house gas emission leading to depletion of the ozone layer with resultant increase in global warming [1]. One of the most attractive alternatives is bio-ethanol-alcohol produced from agricultural crops and residues. Initially, this promising alternative was produced from agricultural crops such as sugar cane, maize, millet, cassava etc. [2].

However, as a result of food-feed competition that

Manuscript received August 27, 2013; revise November 15, 2013.

Abdullahi Bako Rabah and Shuaibu Bala Manga are with Department of Microbiology, Usmanu Danfodiyo University, Sokoto, Nigeria (e-mail: abrabah2009@gmail.com).

Solomon Bankole Oyeleke is with Department of Microbiology, Federal University of Technology, Minna, Nigeria.

Lawal Hassan Gusau is with Department of Chemistry, Usmanu Danfodiyo University, Sokoto, Nigeria. resulted in global food scarcity in the mids 2010s, the focus was shifted to utilization of agricultural wastes that has no economic value to serve as substrate for bioethanol production. This would allow agricultural land to be used more efficiently and at the same time prevent competition with food supplies [3]. The objective of this research is to consider the possibility of utilizing rice husks and groundnut shells both of which are common agricultural wastes in this part of the world for bioethanol production.

\section{MATERIALS AND METHODS}

\section{A. Acid Hydrolysis of Raw Materials}

This was carried out according to the method described by [4]. One hundred grams (100g) each of rice husks and groundnut shells were weighed into 2 litre capacity conical flasks. Then 1 litre of varying dilute hydrochloric acid $(\mathrm{HCl})$ concentrations of $3.0 \%, 4.0 \%$ and $5.0 \%$ were added into the conical flasks. The flasks were covered with cotton wool, wrapped in aluminium foil, heated in a water bath for 20, 25 and 30 minutes at $30{ }^{\circ} \mathrm{C}, 40{ }^{\circ} \mathrm{C}$ and $50{ }^{\circ} \mathrm{C}$ and then autoclaved for 15 minutes at $121{ }^{\circ} \mathrm{C}$. The flasks were allowed to cool, filtered through No1 What man filter paper and the $\mathrm{pH}$ was adjusted to 4.5 with $0.4 \mathrm{M} \mathrm{NaOH}$.

\section{B. Determination of Reducing Sugar}

The reducing sugar content following hydrolysis of the agro wastes was determined using the dinitrosalicylic acid (DNS) colorimetric method [5] and the sample measured at $491 \mathrm{~nm}$ using UV-VIS spectrophotometer (UV-1650pc, Shimadzu). The reducing sugar content was subsequently determined by making reference to a standard curve of known glucose concentrations.

\section{Fermentation of the Hydrolysed Samples}

The fermentation of the hydrolysed samples was carried out in accordance with the methods described by [6]. One hundred milliliters $(100 \mathrm{ml})$ of the rice husks and groundnut shells hydrolysates were dispensed into two sets of twelve different $500 \mathrm{ml}$ capacity conical flasks. The flasks were then covered with cotton wool, wrapped in aluminium foil and autoclaved at $121{ }^{\circ} \mathrm{C}$ for 15 minutes. The flasks were allowed to cool at room temperature and aseptically inoculated with $1 \mathrm{ml}$ suspension $(6.0 \times 102 \mathrm{cfu} / \mathrm{ml})$ of the fermentative organisms isolated in previous study as follows:

1) inoculated with Saccharomyces cerevisiae

2) inoculated with Zymomonasmobilis

3) inoculated with Saccharomyces cerevisiae and Zymomonasmobilis

All the flasks were incubated at $30{ }^{\circ} \mathrm{C}$ for 5 days. 


\section{Determination of Concentration of Bioethanol Produced}

This was carried out using UV-VIS quantitative analysis of alcohols using chromium VI reagent according to the methods described by [7]. A quantity (1 $\mathrm{ml}$ ) of standard ethanol was diluted with $100 \mathrm{ml}$ of distilled water to give a concentration of $1 \%$. Then, each of $0,2,4,6$ and $8 \mathrm{ml}$ of the $1 \%$ ethanol was diluted to 10 $\mathrm{ml}$ with distilled water to produced $0,0.2,0.4,0.6$ and 0.8 $\%$ of the ethanol. To each of the varying ethanol concentrations $2 \mathrm{mls}$ of chromium reagent was added and allowed to stand for an hour for colour development. The absorbance of each concentration was measured at 588 $\mathrm{nm}$ using UV-VIS spectrophotometer (UV-1650pc, Shimadzu) and the readings used to developed standard ethanol curve. Then $5 \mathrm{ml}$ of each bioethanol samples were put in test tubes and treated with $2 \mathrm{mls}$ of the chromium reagent. The mixture was allowed to standard for an hour and the absorbance measured at $588 \mathrm{~nm}$ using the UV-VIS spectrophotometer (UV-1650pc, Shimadzu).

\section{E. Statistical Analysis of Data}

All the works experiments were cobnducted in triplicates. The data sets were expressed as mean \pm standard deviation $(n=3)$. Analysis of variance (ANOVA) was done using One-Way Analysis of Variance to test for the difference in means using the SPSS for Windows, version 15.0. (Chicago IL, USA). Graphs were plotted with Microsoft excel.

\section{RESULTS AND DISCUSSION}

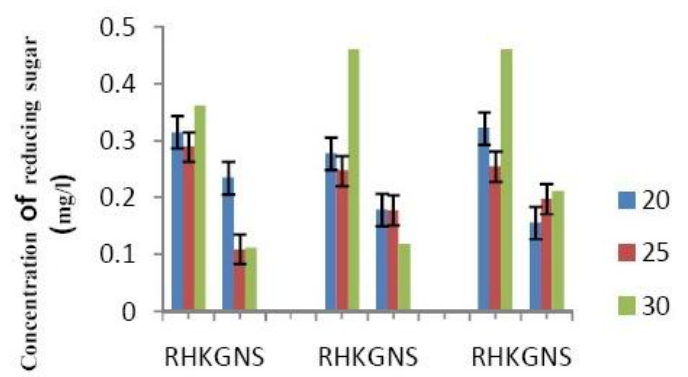

Fig. 1. Reducing sugar yield of hydrolysates hydrolyzedwith $3 \%$ acid at 30,40 and $50^{\circ} \mathrm{C}$ for 20,25 and 30 minutes.

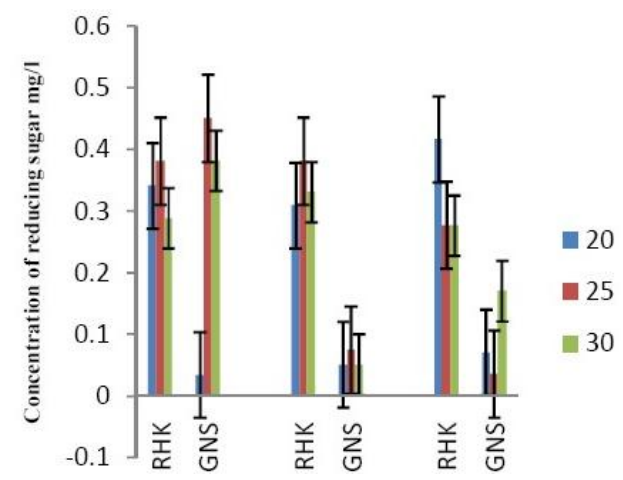

Fig. 2. Reducing sugar yield of hydrolysates hydrolyzed with $4 \%$ acid at 30,40 and $50^{\circ} \mathrm{C}$ for 20,25 and 30 minutes.

In the study, different $\mathrm{HCl}$ acid concentrations (3\%, 4 $\%$ and $5 \%$ ) were used to hydrolyzed rice husks and groundnut shells prior to fermentation. At $3 \%$ concentration the highest yield of reducing sugar of $0.46 \mathrm{mg} / \mathrm{l}$ was obtained from rice husks at $40{ }^{\circ} \mathrm{C}$ and $50{ }^{\circ} \mathrm{C}$ for a period of 30 minutes (Fig. 1). But at $4 \%$ concentration, a reducing sugar yield of $0.45 \mathrm{mg} / \mathrm{l}$ was obtained from groundnut shells at $30^{\circ} \mathrm{C}$ for 25 minutes (Fig. 2).

However, at $5 \%$ concentration a high yield of $0.46 \mathrm{mg} / \mathrm{l}$ was obtained from rice husks and groundnut shells at $30{ }^{\circ} \mathrm{C}$ for 20 minutes and $50{ }^{\circ} \mathrm{C}$ for 30 minutes respectively (Fig. 3).

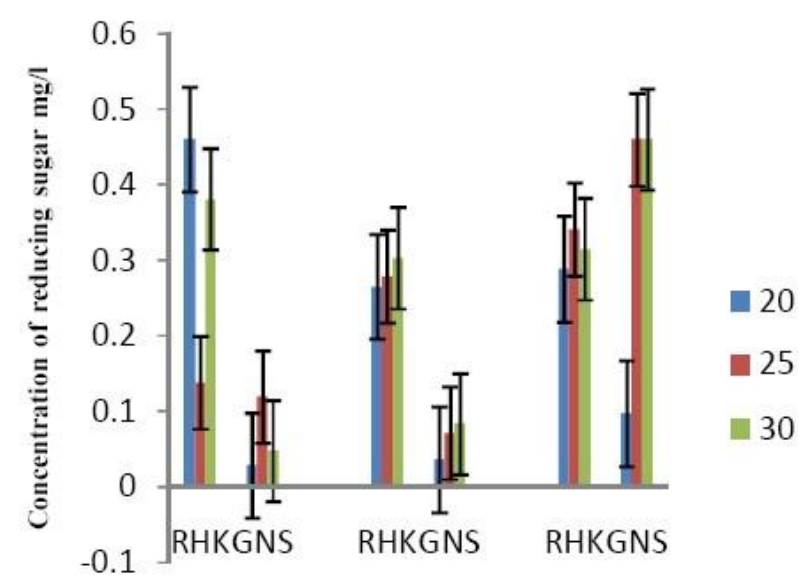

Fig. 3. Reducing sugar yield of hydrolysates hydrolyzed with $5 \%$ acid at 30 , 40 and $50^{\circ} \mathrm{C}$ for 20,25 and 30 minutes.

TABLE I: CONCENTRATION (\%) OF BIOETHANOL PRODUCED FROM RICE HUSK USING SACCHAROMYCES CEREVISIAE, ZYMOMONASMOBILIS AND THE COMBINATION OF SACCHAROMYCES CEREVISIAE AND ZYMOMON AS MOBILIS

\begin{tabular}{|c|c|c|c|}
\hline Days & S. cerevisiae & Z. mobilis & $\begin{array}{c}\text { S. cerevisiae } \\
\text { mobilis }\end{array}$ \\
\hline 1 & $\begin{array}{c}0.580^{\mathrm{a}} \pm 0.03 \\
6\end{array}$ & $0.547^{\mathrm{a}} \pm 0.027$ & $0.524^{\mathrm{a}} \pm 0.024$ \\
\hline 2 & $\begin{array}{c}0.469^{\mathrm{ab}} \pm 0.2 \\
12\end{array}$ & $0.457^{\mathrm{a}} \pm 0.199$ & $0.445^{\mathrm{a}} \pm 0.167$ \\
\hline 3 & $\begin{array}{c}0.351^{\mathrm{bc}} \pm 0.1 \\
66\end{array}$ & $0.422^{\mathrm{a}} \pm 0.184$ & $0.524^{\mathrm{a}} \pm 0.011$ \\
\hline 4 & $\begin{array}{c}0.172^{c} \pm 0.06 \\
4\end{array}$ & $\begin{array}{c}0.152^{\mathrm{b}} \pm 0.05 \\
1\end{array}$ & $0.132^{\mathrm{b}} \pm 0.071$ \\
\hline 5 & $\begin{array}{c}0.149^{c} \pm 0.01 \\
3\end{array}$ & $\begin{array}{c}0.161^{\mathrm{b}} \pm 0.03 \\
8\end{array}$ & $0.147^{\mathrm{b}} \pm 0.061$ \\
\hline 6 & $\begin{array}{c}0.165^{\mathrm{c}} \pm 0.01 \\
0\end{array}$ & $\begin{array}{c}0.161^{\mathrm{b}} \pm 0.01 \\
2\end{array}$ & $0.147^{\mathrm{b}} \pm 0.014$ \\
\hline 7 & $\begin{array}{c}0.188^{c} \pm 0.07 \\
3\end{array}$ & $\begin{array}{c}0.127^{\mathrm{b}} \pm 0.01 \\
9\end{array}$ & $0.128^{\mathrm{b}} \pm 0.035$ \\
\hline $\mathrm{D}(0.05)$ & 0.192 & 0.186 & 0.130 \\
\hline
\end{tabular}

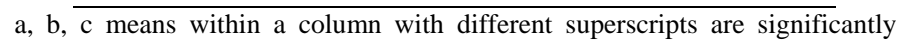
different $(P<0.05)$

Values are mean \pm standard deviations of three replications

The results revealed that Saccharomyces cerevisiae produced its highest bioethanol concentration of $0.580 \pm 0.036 \%$ after 24 hours of fermentation. Similarly, Zymomonasmobilis produced its highest bioethanol concentration of $0.547 \pm 0.042 \% 24$ hours of fermentation while the combination of the two organisms produced their highest yield of $0.524 \pm 0.011 \%$ after third day of fermentation (Table I) from rice husk hydrolysates. However, when groundnut shell hydrolysate was considered the results revealed that Saccharomyces cerevisiae produced its highest bioethanol concentration of $0.358 \pm 0.019 \%$ after 24 hours of fermentation. Similarly, Zymomonasmobilis produced its highest bioethanol concentration of $0.313 \pm 0.045 \%$ after fourth day of fermentation while the combination of the two organisms produced its highest yield of $0.283 \pm 0.01 \%$ after 24 hours of 
fermentation (Table II). The combination of $S$. cerevisiae and $Z$. mobilis produced the highest concentration of bioethanol from rice husk. Similarly, there was no significant difference $(p<0.05)$ between the concentrations of bioethanol produced by the two organisms on the first, second and third day of fermentation. However, the concentration decreased significantly $(p<0.05)$ throughout the remaining period of fermentation.

TABLE II: CONCENTRATION (\%) OF BIOETHANOL PRODUCED FROM GROUNDNUT SHELl USING SACCHAROMYCES CEREVISIAE, ZYMOMONAS MOBILIS AND THE COMBINATION OF SACCHAROMYCES CEREVISIAE AND ZYMOMONAS MOBILIS

\begin{tabular}{cccc}
\hline Days & S. cerevisiae & Z. mobilis & S. cerevisiae+Z. Mobilis \\
\hline 1 & $0.358^{\mathrm{a}} \pm 0.019$ & $\begin{array}{c}0.290^{\mathrm{ab}} \pm 0.0 \\
63\end{array}$ & $0.283^{\mathrm{a}} \pm 0.010$ \\
2 & $0.316^{\mathrm{a}} \pm 0.017$ & $\begin{array}{c}0.235^{\mathrm{ab}} \pm 0.0 \\
31\end{array}$ & $0.233^{\mathrm{ab}} \pm 0.071$ \\
3 & $0.300^{\mathrm{a}} \pm 0.057$ & $\begin{array}{c}0.237^{\mathrm{ab}} \pm 0.0 \\
24\end{array}$ & $0.226^{\mathrm{ab}} \pm 0.019$ \\
4 & $0.283^{\mathrm{a}} \pm 0.108$ & $\begin{array}{c}0.313^{\mathrm{a}} \pm 0.04 \\
5\end{array}$ & $0.207^{\mathrm{b}} \pm 0.019$ \\
5 & $0.288^{\mathrm{a}} \pm 0.050$ & $\begin{array}{c}0.251^{\mathrm{ab}} \pm 0.0 \\
41\end{array}$ & $0.235^{\mathrm{ab}} \pm 0.025$ \\
6 & $\begin{array}{c}0.260^{\mathrm{a}} \pm 0.284 \\
\mathrm{ab}\end{array} 0.246^{\mathrm{a}} \pm$ \\
& 0.014 & & \\
7 & 0.051 & 0.043 & \\
\hline $\begin{array}{c}\text { LSD } \\
(0.05)\end{array}$ & 0.121 & 0.071 & $0.227^{\mathrm{ab}} \pm 0.055$ \\
\hline
\end{tabular}

a,b,c means within a column with different superscripts are significantly different $(P<0.05)$

Values are mean \pm standard deviations of three replications

This may be attributable to the fact that as the organisms fermented the fermentation broth there is the production and accumulation of intermediate co-products that have a detrimental effect on the fermentative organisms and tend to inhibit or slow down their metabolic activity during the remaining period under study. Reference [8] reported that as toxic compounds such as lignin residues, acids and aldehydes accumulated in the fermentation medium the concentration of bioethanol tend to decrease. Also, as the fermentation period increases some quantity of bioethanol may be lost due to the volatility of ethanol. Similarly, thefermentative organisms' inability to ferment pentoses more especially xylose which is the main component of hemicellulose fraction of lignocellulose may be another attributable factor for low bioethanol concentration. However, [9] reported the production of high concentration of bioethanol from molasses with the $\mathrm{pH}$ of fermentation medium adjusted to $\mathrm{pH}$ of 2.5-6. The result is also in agreement with that of [10] who reported that bioethanol yield was high $(7.8 \%)$ at $\mathrm{pH} 4$ and that the range percentage of bioethanol production between $\mathrm{pH} 4$ to 6 did not show the significant difference which only ranged from 7.43 to $7.8 \%$ of ethanol production.

\section{REFERENCES}

[1] P. S. Nigam and A. Singh, "Production of liquid biofuels from renewable resources," Progress in Energy and Combustion Science, vol. 37, pp. 52-68, 2011.
[2] S. N. Naik, V. V. Goud, P. K. Rout, and A. K. Dalai, "Production of first and second generation biofuels, A comprehensive review," Renewable and Sustainable Energy Reviews, vol. 14, pp. 578-597, 2010.

[3] P. Saranraj and D. Stella. "Technologies and modern trends for bioethanol production using cellulosic agricultural wastes," International Journal of Applied Microbiology Science, vol. 1, no. 2, pp. 1-12, 2012.

[4] C. N. Humphrey and U. O. Caritas, "Optimization of ethanol production from Garcinia kola (bitter kola) pulp agro waste," African Journal of Biotechnology, vol. 6, no. 17, pp. 2033-2037, 2007.

[5] G. L. Miller, "Use of dinitrosalicylic acid reagent for determination of reducing sugar," Analytical Chemist, vol. 31, pp. 426, 1959.

[6] A. A. Brooks, "Ethanol production potential of local yeast strains isolated from ripe banana peels," African Journal of Biotechnology, vol. 7, no. 20, pp. 3749-3752, 2008.

[7] S. J. Patel, R. Onkarappa, and K. S. Shobha, "Fungal pretreatment studies on rice husks and bagasse for ethanol production," Electronic Journal of Environmental, Agricultural, and Food Chemistry, vol. 6,no. 4, pp. 19211926, 2007.

[8] H. D. Zakpaa, E. E. Mak-Mensah, and F. S. Johnson, "Production of bioethanol from corncobs using Aspergillusniger and Saccharomyces cerevisae in simultaneous saccharification and fermentation," African Journal of Biotechnology, vol. 8, no. 13, pp. 3018-3022, July 6, 2009.

[9] A. Tahir, M. Aftab, and T. Farasat, "Effect of cultural conditions on ethanol production by locall isolated Saccharomyces cerevisiae BIO-07," Journal of Applied Pharmacy, vol. 3, no. 2, pp. 72-78, 2010.

[10] A. B. M. S. Hossain and A. R. Fazliny, "Creation of alternative energy by bio-ethanol production from pineapple waste and the usage of its properties for engine," African Journal of Microbiology Research, vol. 4 no. 9, pp. 813-819, 2010.

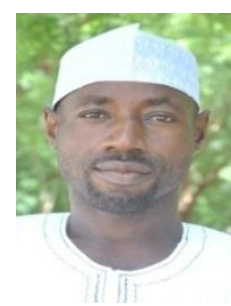

Abdullahi BakoRabah was born in Rabah town of Sokoto State, Nigeria on March 31, 1971. He had secondary school education from Nagarta College, Sokoto. Then proceeded to Usmanu Danfodiyo University, Sokoto where he obtained BSc. Microbiology $2^{\text {nd }}$ class upper division in 1997, MSc. Microbiology in 2008 and Ph.D. Microbiology in 2012. His area of specialization is Environmental Microbiology with interest in biofuels and waste management. In 1999 after finishing his one year compulsory national service, he joined the services of Shehu Shagari College of Education, Sokoto. Then, in 2006 he left the college and joined the services of Usmanu Danfodiyo University, Sokoto, Nigeria as Graduate Assistant (2006), Assistant Lecturer (2008), Lecturer II (2010) and currently waiting for confirmation of my promotion to Lecturer I. Currently he have 19 published articles.

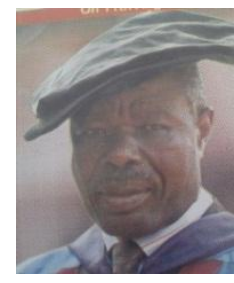

Solomon OyelekeBankole was born on January 15 1953. He obtained his Ph. D. in microbiology in 1998 from the Federal University of Technology, Minna, Nigeria. He joined the services of the University in 1991 and became a Professor of Microbiology in 2009.

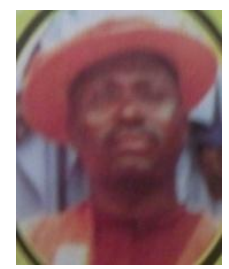

Shuaibu Bala Manga was born on October 12, 1963. He obtained his Ph.D. in microbiology in 1998 from the Federal University of Technology, Minna, Nigeria. He joined the services of the University in 1991 and became a Professor of Microbiology in 2009.

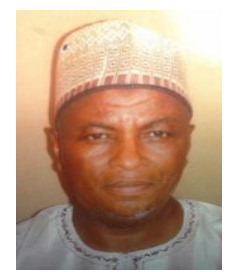

Lawal Hassan Gusau was born in August 1958. He obtained his Ph.D. in chemistry in 2002 from the Usmanu Danfodiyo University, Sokoto, Nigeria. He joined the services of the University in 1985 and became a Professor of Chemistry in 2007. 